\title{
METHODOLOGICAL APPROACHES TO EVALUATING BEER AND NON-ALCOHOLIC PRODUCTS SHELF LIFE
}

\author{
Marina V. Gernet, Elena M. Sevostyanova, Olga A. Soboleva, Irina L. Kovaleva, Irina N. Gribkova* \\ All-Russian Scientific Research Institute of the Brewing, Non-Alcoholic and Wine Industry - \\ Branch of the V.M. Gorbatov Federal Research Center for Food Systems of Russian Academy of Sciences, Moscow, Russia
}

KEY WORDS:

shelf life, storage conditions,

accelerated aging, express method, soft drinks, mineral water, beer

\begin{abstract}
The article discusses the relevance of developing methodological approaches to the beer and soft drinks accelerated aging method in the market. The controlled indicators selection principles, mainly affecting the quality of the finished product, and the basic equation describing the dependence of changes in indicators on the main temperature factor are given. Studies of the influence of various physical factors (temperatures in the range of $50-60{ }^{\circ} \mathrm{C}$, UV-radiation), both individually and jointly, on the physicochemical and organoleptic characteristics of packaged water for various experimental versions did not show statistically significant changes in the normalized parameters of the basic salt and microelement composition investigated water during storage. The optimal mode of accelerated «aging» of packaged water at an elevated temperature (up to $60^{\circ} \mathrm{C}$ ) and UV-radiation was established. In the case of soft drinks, thermostating was used when changing the temperature regimes (heat $50 \pm 2{ }^{\circ} \mathrm{C} /$ cold $6 \pm 2{ }^{\circ} \mathrm{C}$ ) at an exposure time of 30 days, which made it possible to observe a decrease in taste and aroma compared with the control, as well as a decrease in sweetness and the appearance of a slight plastic taste for non-carbonated drink. The influence a temperature regime change on brewing products, which cannot be estimated using the existing method due to the high turbidity, is shown.
\end{abstract}

\section{Introduction}

A food products shelf life is one of the most important indicators characterizing the good or poor quality of product. The expiration dates and storage conditions of beer-non-alcoholic products establishment and confirmation (further, beverages) require special scientific studies on the comparison and scientific justification of temperature and optimal storage selection conditions. Drinks which is circulation on the territory of the Eurasian Economic Union for a specified shelf life, when used for their intended purpose, should be safe [1]. Shelf life and storage conditions for finished products are set by the manufacturer. Basically, drinks (beer, beer drinks, soft drinks, mineral and drinking water) are not perishable products and manufacturers declare shelf life of 6-12 months at different storage temperatures and the manufacturer must confirm the safety of their products throughout the shelf life, taking into account the coefficient reserve (1.15) [2]. Studies on the shelf life and storage conditions establishment for beverages are carried out to confirm compliance of the product with the established hygiene requirements during these periods, as well as to prevent their possible harmful effects on human health and the environment. To reduce the duration of experimental research, methods of «accelerated aging» are increasingly used, which can significantly save time and predict certain quality indicators and shelf life of food products.

The research methodology to justify the drinks shelf life includes the following methodological principles: the controlled indicators choice, establishing the frequency of control, calculating the samples number required for research, developing a program and drawing up a research calendar, conducting research.

The controlled indicators choice is based on ensuring microbiological safety, harmlessness of the physicochemical composition and drinks favorable organoleptic properties. Indicators are selected that are mandatory for control, in accordance with the requirements of current regulatory documents, and indicators that may change during storage, affecting the safety, quality and special properties of drinks.

Establishing the frequency of control. Studies to justify shelf life are carried out at least 3 times during the specified shelf life at the beginning of storage, at the shelf life end and after a period of time determined by the appropriate reserve ratio for products with a planned shelf life of up to 6 months and at least 4 times (optional including mid-life) for products with a planned shelf life of 12 months.

To conduct studies on the justification of expiration dates, typical product samples can be identified. A standard sample is a sample of finished products of the same name, manufactured by one manufacturer in accordance with the normative and technical documentation developed for it that regulates the production of products (technical conditions, technological instructions). The test results of a type sample (each item) apply to the entire volume of products. Physico-chemical, microbiological and organoleptic studies to confirm shelf life are carried out at a temperature declared by the manufacturer.

Previous regulatory documents established the expiration dates of mineral medicinal-canteen and medicinal waters bottled in glass bottles. According to these documents, mineral water is stored in special darkened ventilated warehouses, protected from moisture, at a temperature of 5 to $20^{\circ} \mathrm{C}$. The shelf life of mineral water was established -12 months from the date of bottling $[3,4]$. For drinking water: shelf life of 12 months at a temperature of 2 to $20{ }^{\circ} \mathrm{C}[5]$. A soft drinks shelf life was more than 30 days, the storage temperature was $18^{\circ} \mathrm{C}[6]$ For pasteurized and unpasteurized beer, according to $[7,8]$, the storage temperature was $10-20^{\circ} \mathrm{C}$ and $5-12{ }^{\circ} \mathrm{C}$, respectively. The pasteurized beer shelf life prepared using protein-colloidal stability stabilizers is three months, without the use of stabilizers, a month from the date of bottling.

At the same time, in the storing drinks process (especially in trade), the storage temperature regimes are not observed, and the shelf life dependence on the material and the volume of consumer packaging is revealed.

Our previous studies found that various hydrochemical types and mineralization mineral waters, packaged in polymer or glass packaging, for 15 months at temperature $25 \pm 2{ }^{\circ} \mathrm{C}$ were in compliance with the requirements of current regulatory documents on organoleptic indicators, basic salt composition, microbiological and chemical safety [9]. At present, the drinks shelf life, subject to storage conditions in polymer packaging is from 3 months to 18 months, in glass - up to 24 months: a specific period is 
set individually for various drinks. As a result of the research, a research methodology was developed to justify the mineral waters shelf life and Methodological guidelines to justify mineral waters of various groups shelf life and storage temperature conditions [10].

One of the promising directions for assessing changes in the long-term food products quality is the «accelerated aging» method, which can significantly save time and predict certain quality indicators and food products shelf life, especially newly developed ones. Such testing is carried out due to the intensification of the many factors impact causing food spoilage $[11,12,13,14,15]$.

When using the method, a situation is created specially in which the spoilage period and the chemical reaction kinetic factor value are significantly accelerated in time, and the transience of the reaction becomes quite high. Moreover, the product goes through its «spoilage life cycle» in a relatively short period of time. All tests are carried out at a temperature significantly exceeding its possible values during the actual storage of products, which allows to intensify the processes causing food spoilage.

Accelerated Shelf Life Testing (ASLT) method and its combined variants allow to obtain a forecast for some products within only 10-15 days (instead of a year). The process kinetic model is the Arrhenius equation. According to this equation, with a temperature increase of $10^{\circ} \mathrm{C}$, the chemical reactions transience doubles, including in such products: balms, sweets, drinks, various creams, etc. The ASLT method was used by a number of authors, both foreign and domestic, to determine the functional drinks shelf life [16]. Controlled indicators selected: the mass fraction of anthocyanins and the total content of phenolic substances, organoleptic indicators (color, smell, taste). The tests were carried out at an elevated temperature of $60^{\circ} \mathrm{C}$, the maximum possible at which the Arrhenius law is valid. It was revealed that at temperature $60{ }^{\circ} \mathrm{C}$ the degradation of anthocyanins and phenolic substances occurred on the 7th day, which corresponds to 3.7 months of storage under standard conditions.

In the non-alcoholic industry, work on substantiating expiration dates was carried out by researchers on non-alcoholic bases with a standard 2 years shelf life [17]. Simultaneously with the bases storage under standard conditions, their «accelerated aging» was carried out. Experimental studies were carried out at temperatures $\left({ }^{\circ} \mathrm{C}\right): 40,50$, and 60 , since the information obtained using accelerated methods at three different temperatures is sufficient to obtain satisfactory and reliable results for predicting shelf life. The balsams quality loss was determined by the change in normalized indicators (acidity, appearance, etc.) and by the decrease in the flavonoids and tannins mass fraction (as an estimate of the physiological value of balsams).

For drinking and mineral water, work on the substantiation of shelf life by accelerated methods was not carried out.

In the brewing industry, the cyclic express method was used to predict the shelf life of light beer. Beer samples were kept at a temperature of $60{ }^{\circ} \mathrm{C}$ for 24 hours, then cooled to room temperature and placed in a thermostat for 24 hours at temperature $0{ }^{\circ} \mathrm{C}$. Beer quality loss was determined by the indicator «turbidity» at temperature $20^{\circ} \mathrm{C}$. The cycle: «heating-cooling» is repeated until the average turbidity exceeds 2.0 EMU (turbidity units according to the European Brewing Convention standards) or opalescence is not observed. One heating cycle corresponds to one month of beer storage [18].

The fact is that this technique is based on the implementation of a shift in colloidal equilibrium in beer, which is caused by the appearance of turbidity in the finished drink [19]. The association of polyphenol-protein associates takes place, which is called the term «irreversible turbidity», which gives reason to talk about spoilage of the beer under study. Substances of non-carbohydrate nature can also join the above associates [20].
Thus, the express methods development for predicting the drinks shelf life and a methodological approach to justifying shelf life is an important scientific task for the beer-non-alcoholic industry.

The main objectives of the experimental studies were:

$\square$ research and scientific justification of factors providing accelerated brewing and non-alcoholic products aging;

$\square$ a study of the physico-chemical and microbiological parameters brewing and non-alcoholic products stability depending on the volume of consumer packaging and its corking under storage conditions that provide accelerated aging of drinks; $\square$ comparative studies of the drinks with natural and accelerated aging stability and quality.

\section{Materials and methods}

The experimental work was carried out in the brewing technology department in conjunction with the Testing Center of the AllRussian Scientific Research Institute of the Brewing, Non-Alcoholic and Wine Industry. A various hydrochemical types, carbonated and non-carbonated mineral waters, soft drinks with sugar and sweeteners of various compositions, unfiltered pasteurized beer, including wheat, packaged in consumer packaging made of polyethylene terephthalate and glass, were chosen as objects of study.

For mineral water samples, the experimental conditions were chosen: temperature $60^{\circ} \mathrm{C}$, UV-radiation $(\lambda=254 \mathrm{~nm})$, exposure time 30 days. The packaged mineral water samples were placed in a thermostat, in which they were kept for a given time. Daily part of the mineral water samples were irradiated for 15 minutes. Sampling was carried out on the 15 th and 30th day of the experiment. Control samples were stored at room temperature $25 \pm 2{ }^{\circ} \mathrm{C}$ without access to direct sunlight for 30 days.

The temperature regime for soft drinks was tested in 3 versions of the experiment - constant heating, heat / cold with slow cooling, heat / cold with fast cooling. The temperature was: heat $50 \pm 2{ }^{\circ} \mathrm{C} /$ cold $6 \pm 2{ }^{\circ} \mathrm{C}$, exposure time 30 days. Samples were exposed in a cyclic mode. One cycle was 48 hours and repeated for a month. Control samples $(\mathrm{K})$ were stored at a temperature of $25 \pm 2{ }^{\circ} \mathrm{C}$ for 30 days.

The drinks quality was evaluated by organoleptic (smell, taste) and physico-chemical indicators.

Organoleptic evaluation of drinks was carried out using a 25 -point system for carbonated and a 19-point system for noncarbonated products. The tasting was carried out by a closed method. The quality of mineral waters was evaluated by the following criteria: appearance, taste and smell, carbon dioxide saturation. The quality of soft drinks was evaluated according to the following criteria: transparency (for transparent drinks), opalescence (for drinks based on vegetable raw materials), color, appearance, taste and aroma, and carbon dioxide saturation.

Physico-chemical parameters of the beer under study (initial and artificially aged) - turbidity - were determined using a turbidimeter (Hazemeter 600). The technique is based on the measurement of turbidity in beer samples using a turbidimeter device expressing the turbidity intensity in EBC units, measured at an angle of 90 and 25 degrees for various types of colloidal and non-colloidal particles [21].

\section{Results and discussion}

For mineral and drinking water, the following factors were selected as factors affecting the quality of products: temperature $\left(50-60{ }^{\circ} \mathrm{C}\right), \mathrm{UV}$-radiation, and their combined effect. The packaged waters physicochemical parameter studies under various experimental variants did not show statistically significant changes in the basic salt and microelement composition normalized indicators in studied water samples during storage. It has been established that the most optimal mode of accelerated «aging» 
of packaged water is thermostating at elevated temperatures (up to $60^{\circ} \mathrm{C}$ ) $+\mathrm{UV}$-radiation. At the same time, for carbonated water in PET packaging, it is necessary to select a temperature regime that excludes the closure spontaneous opening and shape loss bottle possibility.

An important indicator and almost the only one by which the consumer evaluates the mineral and drinking water quality is the organoleptic assessment. Organoleptic characteristics include color, turbidity (transparency), smell, taste and taste.

Organoleptic evaluation of the mineral waters quality with various processing methods is presented in Table 1.

Organoleptic evaluation of packaged water samples

\begin{tabular}{|c|c|c|c|c|c|}
\hline \multirow{2}{*}{$\begin{array}{l}\text { Sample } \\
\text { code }\end{array}$} & \multirow{2}{*}{ Processing method } & \multirow{2}{*}{$\begin{array}{l}\text { Norm } \\
\text { (points) }\end{array}$} & \multicolumn{3}{|c|}{$\begin{array}{l}\text { Organoleptic } \\
\text { evaluation } \\
\text { (points) }\end{array}$} \\
\hline & & & $\mathbf{K}$ & $\begin{array}{l}15 \\
\text { days }\end{array}$ & $\begin{array}{l}30 \\
\text { days }\end{array}$ \\
\hline \multicolumn{6}{|c|}{ still } \\
\hline $1-1$ & at temperature $60^{\circ} \mathrm{C}$ & \multirow{3}{*}{$\begin{array}{c}\text { Excelent 17-19 } \\
\text { Good 15-17 } \\
\text { Satisfactorily 14-15 }\end{array}$} & 18.0 & 17.7 & 16.2 \\
\hline \multirow[t]{2}{*}{$2-1$} & $\begin{array}{l}\text { at temperature } 60^{\circ} \mathrm{C} \\
\text { and UV-radiation }\end{array}$ & & 18.5 & 14.8 & 13.5 \\
\hline & UV-radiation & & 18.5 & 18.2 & 17.5 \\
\hline \multicolumn{6}{|c|}{ sparkling } \\
\hline $1-2$ & at temperature $60^{\circ} \mathrm{C}$ & \multirow{6}{*}{$\begin{array}{c}\text { Excelent 22-25 } \\
\text { Good 19-22 } \\
\text { Satisfactorily 15-19 }\end{array}$} & 23.8 & 20.0 & 18.0 \\
\hline $1-3$ & at temperature $60^{\circ} \mathrm{C}$ & & 25.0 & 24.2 & 21.8 \\
\hline \multirow{2}{*}{$2-2$} & $\begin{array}{l}\text { at temperature } 60^{\circ} \mathrm{C} \\
+ \text { UV-radiation }\end{array}$ & & 24.5 & 16.8 & 15.0 \\
\hline & UV-radiation & & 24.5 & 24.5 & 24.3 \\
\hline \multirow[t]{2}{*}{$3-1$} & $\begin{array}{l}\text { at temperature } 50^{\circ} \mathrm{C} \\
\text { and UV-radiation }\end{array}$ & & 24.0 & 23.8 & 21.5 \\
\hline & UV-radiation & & 24.0 & 24.0 & 24.0 \\
\hline
\end{tabular}

It was found that during storage at $60{ }^{\circ} \mathrm{C}$ in non-carbonated mineral water for 30 days there is a slight decrease in organoleptic characteristics (light extraneous taste) by the end of the experiment. Additional UV-radiation treatment leads to a faster decline (to taste - the appearance of a chemical aftertaste and bitterness). The UV-radiation treatment of mineral water stored at room temperature does not significantly affect on still mineral water organoleptic characteristics. For sparkling water, joint treatment (temperature and UV-radiation) also leads to a rapid decrease in organoleptic characteristics during storage for 30 days. At temperature $50{ }^{\circ} \mathrm{C}$, a marked change in organoleptic characteristics in the studied mineral waters was not observed for 2 months.

Deterioration of organoleptic characteristics can be explained by significant disadvantages of PET packaging, such as relatively low barrier properties (it passes ultraviolet rays and oxygen into the bottle, and carbon dioxide to the outside, which degrades the quality and shortens the shelf life of products) and poor resistance to heat.

As samples of research on non-alcoholic products, 4 samples of industrially made non-alcoholic drinks based on sugar and / or sweeteners spilled in PET and glass packaging of various capacities were selected.

In accordance with the research program, the task was set - to select the conditions and terms for the experimental work on the «accelerated aging» of soft drinks, allowing to predict the products quality and safety in accordance with modern requirements.

Based on literature data and our own research, the experiment conditions were selected: temperature conditions (heat $50 \pm 2{ }^{\circ} \mathrm{C}$ / cold $6 \pm 2{ }^{\circ} \mathrm{C}$ ), exposure time 30 days. The soft drinks samples were placed in a thermostat, in which they were kept for a given time. The temperature regimes were tested in 3 versions of the experiment - constant heating, heat / cold with slow cooling, heat / cold with fast cooling. One cycle was 48 hours and repeated for a month. Control samples $(\mathrm{K})$ were stored at a temperature of $\left(25 \pm 2{ }^{\circ} \mathrm{C}\right)$ for 30 days.

The results of organoleptic evaluation are presented in Table 2.

Table 2

Organoleptic evaluation of samples of soft drinks

\begin{tabular}{|c|c|c|c|c|c|}
\hline \multirow[t]{2}{*}{ № } & \multirow{2}{*}{$\begin{array}{l}\text { Sample } \\
\text { code }\end{array}$} & \multirow{2}{*}{$\begin{array}{c}\text { Type } \\
\text { of drink }\end{array}$} & \multirow{2}{*}{ Processing method } & \multicolumn{2}{|c|}{$\begin{array}{c}\text { Organoleptic } \\
\text { evaluation (points) }\end{array}$} \\
\hline & & & & $\mathbf{K}$ & 30 days \\
\hline 1. & $1-1-1$ & still & \multirow{4}{*}{$\begin{array}{l}\text { at temperature } 50{ }^{\circ} \mathrm{C} \\
\text { /slow cooling/ at } \\
\text { temperature } 6{ }^{\circ} \mathrm{C}\end{array}$} & 18.6 & 14.2 \\
\hline 2. & $1-2-1$ & sparkling & & 23.8 & 22.0 \\
\hline 3. & $1-3-1$ & sparkling & & 24.8 & 23.4 \\
\hline 4. & $1-4-1$ & sparkling & & 24.2 & 18,9 \\
\hline 5. & $1-1-2$ & still & \multirow{4}{*}{$\begin{array}{c}\text { at temperature } 50{ }^{\circ} \mathrm{C} \\
\text { / quick cooling / at } \\
\text { temperature } 6{ }^{\circ} \mathrm{C}\end{array}$} & 18.6 & 16.4 \\
\hline 6. & $1-2-2$ & sparkling & & 23.8 & 22.0 \\
\hline 7. & $1-3-2$ & sparkling & & 24.8 & 23.2 \\
\hline 8. & $1-4-2$ & sparkling & & 24.2 & 18.5 \\
\hline 9. & $1-1-3$ & still & \multirow{4}{*}{ at temperature $50^{\circ} \mathrm{C}$} & 18.6 & 17.2 \\
\hline 10. & $1-2-3$ & sparkling & & 23.8 & 21.8 \\
\hline 11. & $1-3-3$ & sparkling & & 24.8 & 23.4 \\
\hline 12. & $1-4-3$ & sparkling & & 24.2 & 17.5 \\
\hline
\end{tabular}

Sparkling and still drinks (control) were characterized by a general mark «excellent». In all variants of the experiment, a decrease in taste and aroma was observed in comparison with the control, a decrease in sweetness and the appearance of a weak smack of plastic for a non-carbonated drink were noted. The greatest deterioration in organoleptic characteristics was noted in the sample aged according to experiment 1 (at temperature $50{ }^{\circ} \mathrm{C}$ / slow cooling / at temperature $6{ }^{\circ} \mathrm{C}$ ), as well as in the drink aged according to experiment 3 (at temperature $50^{\circ} \mathrm{C}$ ). It is assumed that this is due to the lemon juice presence in the drink composition, which is extremely unstable during storage (prone to oxidation and tarring).

Unfiltered pasteurized beer, including wheat malt in glass consumer packaging, was chosen as a sample for researching brewing products.

At the first stage of the study, it was necessary to verify the compliance of the industry-approved methodology for beer «accelerated aging» with these product samples [18]. The experimental data are presented in Table 3.

Table. 3.

The unfiltered beer with different composition of raw materials turbidity indicators

\begin{tabular}{lcc}
\hline \multicolumn{1}{c}{ Grain raw materials } & \multicolumn{2}{c}{ Turbidity, un. $\mathbf{E B C}$} \\
\cline { 2 - 3 } & $\mathbf{H}_{\mathbf{9 0}}$ & $\mathbf{H}_{\mathbf{2 5}}$ \\
\hline Lighte barley malt & 86.79 & 55.21 \\
\hline Lighte barley malt & 43.03 & 37.59 \\
\hline Lighte barley malt, wheat malt & 99.99 & 99.99 \\
\hline Lighte barley malt & 72.85 & 53.29 \\
\hline Lighte and dark barley malt & 68.96 & 70.0 \\
\hline Lighte barley malt, wheat malt & 99.99 & 92.78 \\
\hline
\end{tabular}

It should be noted that a reliable measurement of turbidity on the device is possible only in beer with a turbidity in the range of $0.5-30$ units EBC.

The experiments showed (Table 3 data) that in most of the analyzed unfiltered beer samples, the turbidity was either 1.5-3 times higher or not measured at all by the apparatus, as in the case of wheat beer, which is caused by the composition of the wheat malt grain endosperm. The studied beer color characteristics did not affect the turbidity, but only the presence in the beer volume of yeast cells or colloidal compounds corresponding to the characteristics of the used grain raw materials. 
Therefore, now the task has arisen of monitoring significant physicochemical parameters, based on which it would be possible to quantitatively determine the imbalance of colloidal equilibrium and, accordingly, to develop a method of accelerated aging for brewing products.

\section{Conclusions}

Thus, the obtained materials analysis showed the need for further research on the factors and conditions selection affecting the drinks stability during storage. As a result of the work carried out, it was found that for packaged water, an objective indicator of quality confirmation is the organoleptic characteristics (taste, smell and other parameters) and physico-chemical indicators indicating a change in product quality over the expiration date. For soft drinks and beer, given their wide variety, it is necessary to select the optimal factors for accelerated aging processes and scientifically based indicators for control. The research methodology to justify the beverages shelf life using accelerated aging methods will be refined after the research.

\section{REFERENCES}

1. Konietzko, T. (2003). HACCP: An Applied Approach. Chapter 7 in the book 1. Beverage Ouality and Safety. CRC Press LLC. ISBN 058716011-0. DOI: 10.1201/9780203491201.ch7

2. Kilkast, D., Subramanian, P. (2012). Stability and expiration dates. Soft drinks, juices, beer and wine. St. Petersburg: Professia. -440 p. ISBN 978-5-904757-44-1. (in Russian)

3. Dominic Man, C.M. (2015). Determining shelf life in practice. Chapter 3 in the book Shelf Life. pp. 79-99. ISBN9781118346266. DOI: 10.1002/9781118346235.ch3.

4. Phimolsiripol, Y., Suppakul, P. (2016). Techniques in Shelf Life Evaluation of Food Products. Reference Module in Food Science, 1-8. DOI: 10.1016/ B978-0-08-100596-5.03293-5

5. Moody, R. (2005). Broadband Toxicity Sensing for Rapid Surveys of Drinking Water Storage Facilities. Proceedings of OCEANS2005 MTS/IEEE, Washington: IEEE. DOI: 10.1109/oceans.2005.1639959.

6. Pearce, K., Culbert, J., Cass, D., Cozzolino, D., Wilkinson, K. (2016) Influence of Sample Storage on the Composition of Carbonated Beverages by MIR Spectroscopy. Beverages, 2(4), 26. DOI: 10.3390/beverages 2040026

7. Jaskula-Goiris, B., De Causmaecker, B., De Rouck, G., Aerts, G., Paternoster, A., Braet, J., De Cooman, L. (2018). Influence of transport and storage conditions on beer quality and flavour stability. Journal of the Institute of Brewing, 125(1), 60-68. DOI: 10.1002/jib.535

8. Corzo, O., Bracho, N. (2006). Prediction of the sensory quality of canned beer by oxygen concentration, physical chemistry and storage conditions. Journal of Food Science, 69 (7), 285-289. DOI: 10.1111/j.1365-2621.2004. tb13630.x

9. Sevostyanova, E.M., Khorosheva, E.V., Remneva, G.A. (2016). Rationale for Shelf Life and Storage Temperature Conditions of Different Groups of Mineral Waters. Beer and Beverages, 3,46-49. (in Russian)

10. Sevostyanova, E.M. (2016). The Methodical Approach to the Justification of the Shelf Life of Mineral Water. Beer and Beverages, 6,10-12. (in Russian)
11. Stelle, P. (2008). Food shelf life: calculation and testing. St. Petersburg: Professia. - 480 p. ISBN 5-93913-100-X. (in Russian)

12. Valentas, K., Rotshtejn, E., Singh, R.P. (2004). Food Engineering: A Handbook. St. Petersburg: Professia. -386 p. ISBN 5-93913-045-3. (in Russian)

13. Dantas Kabral, A.K., Kosta Fernandis M.E. (1984). General characteristics of the shelf life of food products. M.: VP, I -16261. - $189 \mathrm{p}$. ISBN 5-93914-063-4. (in Russian)

14. Stärker, C., Welle, F. (2019). Migration of Bisphenol A from Can Coatings into Beverages at the End of Shelf Life Compared to Regulated Test Conditions. Beverages, 5(1), 3. DOI: 10.3390/beverages5010003

15. Moazzem, M. S., Sikder, M. B. H., Zzaman, W. (2019). Shelf-Life Extension of Wood Apple Beverages Maintaining Consumption-Safe Parameters and Sensory Qualities. Beverages, 5(1), 25. DOI: 10.3390/beverages 5010025

16. O'Sullivan, M. G. (2012). Principles of sensory shelf-life evaluation and its application to alcoholic beverages. Chapter 3 in the book Alcoholic Beverages, 42-65. DOI: 10.1533/9780857095176.1.42

17. Chorna, T, Yanushkevych, D., Afanasieva, V. (2018). Modern Aspects of Safety Assessment of Foodstuff. Path of Science, 4(4), 4001-4012. DOI: 10.22178/pos.33-7

18. Steiner, E., Becker, T., Gastl, M. (2010). Turbidity and haze formation in beer-insights and overview. Journal of the Institute of Brewing, 116(4), 360-368. DOI:

19. Buiatti, S., Bertoli, S., Passaghe, P. (2017). Influence of gluten-free adjuncts on beer colloidal stability. European Food Research and Technology, 244(5), 903-912. DOI: 10.1007/s00217-017-3010-3

20. Jin Y.-L., R. Speers A., Paulson A.T., Stewart R.J. (2004). Barley $\beta$-glucans and their degradation during malting and brewing, MBAA TQ,110 (2), 104-116. DOI: 10.1002/j.2050-0416.2004.tb00189)

21. Briggs, D.E., Hough, J.S., Stevens, T., Yong T.W. (1999). Malting and brwering science: hopped wort and beer. An Aspen publication, Gaithesburg, Maryland, USA, 821-837. ISBN 0-8342-1684-1

\section{AUTHOR INFORMATION}

Marina V. Gernet - professor, doctor of technical sciences, head of brewing technology department All-Russian Scientific Research Institute of Brewing, Beverage and Wine Industry - Branch of V.M. Gorbatov Federal Research Center for Food Systems of RAS, 119021, Moscow, Rossolimo str., 7. Tel.: +7-499-24510-79, e-mail: institut-beer@mail.ru

Elena M. Sevostyanova - candidate of biological sciences, leading researcher of brewing technology department, All-Russian Scientific Research Institute of Brewing, Beverage and Wine Industry - Branch of V.M. Gorbatov Federal Research Center for Food Systems of RAS, 119021, Moscow, Rossolimo str., 7. Tel.: +7-499-246-01-96, e-mail: waterlena@list.ru

Olga A. Soboleva - candidate of technical sciences, leading researcher of brewing technology department, All-Russian Scientific Research Institute of Brewing, Beverage and Wine Industry - Branch of V.M. Gorbatov Federal Research Center for Food Systems of RAS, 119021, Moscow, Rossolimo str., 7, Tel.: +7-499-24683-10, e-mail: olgasoboleva@mail.ru

Irina L. Kovaleva - senior researcher of brewing technology department, All-Russian Scientific Research Institute of Brewing, Beverage and Wine Industry Branch of V.M. Gorbatov Federal Research Center for Food Systems of RAS, 119021, Moscow, Rossolimo str., 7. Tel.: +7-499-246-83-10, e-mail: kovalevail@ mail.ru

Irina N. Gribkova - candidate of technical sciences, senior researcher of brewing technology department, All-Russian Scientific Research Institute of Brewing, Beverage and Wine Industry - Branch of V.M. Gorbatov Federal Research Center for Food Systems of RAS, 119021, Moscow, Rossolimo str., 7. Tel.: +7-499-24604-47, e-mail: institut-beer@mail.ru

*corresponding author

Authors are equally relevant to the writing of the manuscript, and equally responsible for plagiarism

The authors declare no conflict of interest

Received 15.05.2019 Accepted in revised 07.08.2019 Accepted for publication 02.09.2019 


\title{
SEARCH FOR ALTERNATIVE SOURCES OF NATURAL PLANT ANTIOXIDANTS FOR FOOD INDUSTRY
}

\author{
Nadezhda V. Kupaeva ${ }^{1,2 *}$, Elena A. Kotenkova ${ }^{1}$ \\ ${ }^{1}$ V.M. Gorbatov Federal Research Center for Food Systems of Russian Academy of Sciences, Moscow, Russia \\ ${ }^{2}$ Dmitry Mendeleev University of Chemical Technology of Russia, Moscow, Russia
}

\section{KEY WORDS:}

plant antioxidant, total antioxidant capacity, ORAC, FRAP, efficient environmental management, waste processing

\begin{abstract}
According to the data of the Food and Agriculture Organization of the United Nations, global food losses are about one third of their total output, mainly due to spoilage. Therefore, a search for safe methods of shelf life extension is an important task, especially for products for specialized nutrition. According to literature data, natural antioxidants can be alternative to existing preservatives due to its ability to inhibit oxidation of the main nutrients. Pulp, seeds and peel of quince, apple «Simirenko», feijoa, persimmon, Jerusalem artichoke, white, red and yellow onion were objects of the study. The total antioxidant capacity was determined by Oxygen Radical Absorbance Capacity (ORAC) and Ferric Reducing Antioxidant Power (FRAP) methods and expressed in $\mu \mathrm{mol}$ equiv. Trolox / $\mathrm{g}$ of sample and $\mu$ mol equiv. Dihydroquercetin / $g$ of sample. It was noticed that peels demonstrated higher antioxidant activity, and red onion husk possessed the highest value, which was $722.8 \pm 13.9 \mu \mathrm{mol}$ equiv. Dihydroquercetin / $\mathrm{g}$ of sample and $3357.5 \pm 42.2 \mu \mathrm{mol}$ equiv. Trolox / $\mathrm{g}$ of sample. It was shown that the use of fruit and vegetable wastes is promising for production of food-grade antioxidants. In addition, the results of the research could facilitate stimulation of rational and efficient environmental management.
\end{abstract}

\section{Introduction}

In the developed countries, an amount of food waste increases every year. According to Food and Agriculture Organization of the United Nations (FAO) data, one third of all food produced in the world is either lost or wasted, which is about 1.3 billion tons per year [1]. In this connection, the industry faces an emergent need for improvement of existing or development of new approaches to shelf life extension. Nowadays, there are several main approaches: technological, physical and chemical treatment [2], among which the latter could be potentially dangerous to human health. For example, food preservatives include E200-E299 and some of them are forbidden for the use in several countries depending on the legislation [3,4]. Synthetic preservatives are in demand due to cost-efficiency; therefore, their use is widespread [5,6].

Nowadays, a search for alternative sources of natural preservatives is relevant, because negative effect of synthetic preservatives on health was proven [7,8]. Moreover, a demand for healthy foods is growing and an assortment of functional and specialized products is increasing, including foods for breastfeeding and pregnant women, children and adolescents. Thus, plant antioxidants could be an alternative source of natural preserving agents. It is known that natural antioxidants (AO) in the composition of plant extracts and in a form of mono-substances are widely used both as natural preservatives and as functional additives. The antioxidants with the proved positive effect include dihydroquercetin, tocopherol, vitamin $C$ and others $[9,10,11]$.

In this research, the antioxidant potential of several plants including their pulp, peel and seeds was determined. The antioxidant potential of the samples was determined by Oxygen Radical Absorbance Capacity (ORAC) and Ferric Reducing Antioxidant Power (FRAP) methods.

\section{Materials and methods}

Guince, apple «Simirenko», feijoa, persimmon, Jerusalem artichoke, white, red and yellow onion were objects of the study. Raw materials were bought in the store «VkusVill». For more detailed analysis, their peel, pulp and seeds were analyzed separately depending on the plant. The list of samples is given in Table 1.
Table 1

The list of plant samples

\begin{tabular}{llcccc}
\hline № & Objects & $\begin{array}{c}\text { Peel } \\
\text { (top } \\
\text { layer) }\end{array}$ & Peel & Pulp & Seeds \\
\hline 1 & Quince (harvest of 2018) & - & 1.1 & 1.2 & 1.3 \\
\hline 2 & Apple («Simirenko», harvest of 2018) & - & 2.1 & 2.2 & 2.3 \\
\hline 3 & Feijoa (Azerbaijan, harvest of 2018) & - & 3.1 & 3.2 & $3.3^{*}$ \\
\hline & $\begin{array}{l}\text { Persimmon («Shish Burun», } \\
\text { Azerbaijan) }\end{array}$ & - & 4.1 & 4.2 & - \\
\hline 5 & Jerusalem artichoke & - & 5.1 & 5.2 & - \\
\hline 6 & Yellow onion & 6.1 & 6.2 & 6.3 & - \\
\hline 7 & White onion & - & 7.1 & 7.2 & - \\
\hline 8 & Red onion & - & 8.1 & 8.2 & - \\
\hline "pulp with seeds & & & & \\
\hline
\end{tabular}

Aqueous extracts were prepared for analysis. $1 \mathrm{~g}$ of a minced sample was mixed with $50 \mathrm{ml}$ of boiled distilled water and infused for $15 \mathrm{~min}$ in a closed container with periodic mixing. After that, extracts were filtered through filter paper. The extract of sample 1.3 was centrifuged at $3500 \mathrm{G}$ for 5 min in SIGMA 3 30KS centrifuge («Sigma Laborzentrifugen», Germany). The obtained water extracts were stored at $4^{\circ} \mathrm{C}$ not more than 3 days.

Total antioxidant capacity (TAC) of extracts was determined by fluorescent ORAC method and expressed in $\mu$ mol equiv. Trolox / $g$ of sample. The measurements were carried out on Fluoroskan Ascent FL (TermoLabsystems, Finland) with the use of black 96-well plates by the method [12] in our own modification [13].

The total antioxidant capacity of extracts was determined by the photometric FRAP method on a spectrophotometer SF-2000 (OCB «Spectr», Russia) using the methodology [14] in our own modification [13]. Results were expressed in $\mu$ mol equiv. Dihydroquercetin / $\mathrm{g}$ of sample.

STATISTICA 10.0 software was used in this study for the statistical analyses. The results were calculated as «middle value \pm standard error» $(\mathrm{M} \pm \mathrm{SE})$. Significant differences were tested by one-way ANOVA, followed by the Tukey test. Differences with P-values less than 0.05 were considered as statistically significant. 


\section{Results and discussion}

The indicators of the antioxidant potential of the selected samples were analyzed by the ORAC method (determination of antioxidants absorbance capacity in regard to oxygen radicals (ROO• and RO•)), and by the FRAP method (determination of total antioxidant capacity of a sample). The antioxidant potential was measured in difference parts of the selected samples, such as peel, pulp and seeds. The results are presented in Table 2.

Results of determination of the antioxidant capacity of the selected samples by the ORAC and FRAP methods

\begin{tabular}{|c|c|c|c|}
\hline № & $\begin{array}{l}\text { Part of } \\
\text { samples }\end{array}$ & $\begin{array}{l}\text { FRAP ( } \mu \text { mol equiv. } \\
\text { Dihydroquercetin / } g \\
\text { of sample) }\end{array}$ & $\begin{array}{c}\text { ORAC } \\
\text { ( } \mu \text { mol equiv. } \\
\text { Trolox / } \mathrm{g} \text { of sample) }\end{array}$ \\
\hline \multicolumn{4}{|c|}{ 1. Quince (harvest of 2018) } \\
\hline 1.1 & Peel & $232.5 \pm 8.5^{\mathrm{a}}$ & $918.7 \pm 16.4$ \\
\hline 1.2 & Pulp & $15.8 \pm 1.5^{b, c}$ & BDL \\
\hline 1.3 & Seeds & $3.1 \pm 0.2^{\mathrm{b}, \mathrm{d}}$ & BDL \\
\hline
\end{tabular}

2. Apple («Simirenko», harvest of 2018)

\begin{tabular}{lccc}
\hline 2.1 & Peel & $119.5 \pm 4.8^{\mathrm{a}}$ & $541.3^{2} \pm 29.3^{\mathrm{a}}$ \\
\hline 2.2 & Pulp & $20.3 \pm 1.4^{\mathrm{b}, \mathrm{c}}$ & BDL \\
\hline 2.3 & Seeds & $63.0 \pm 0.8^{\mathrm{b}, \mathrm{d}}$ & $113.7 \pm 15.4^{\mathrm{b}}$ \\
& & 3. Feijoa (Azerbaijan, harvest of 2018) \\
\hline 3.1 & Peel & $302.5^{ \pm} \pm 8.8^{\mathrm{a}}$ & $553.1 \pm 4.7^{\mathrm{a}}$ \\
\hline 3.2 & Pulp & $145.2^{\mathrm{a}} \pm 5.2^{\mathrm{b} . \mathrm{c}}$ & $160.3 \pm 27.1^{\mathrm{b}, \mathrm{c}}$ \\
3.3 & Pulp with seeds & $45.0 \pm 2.0^{\mathrm{b}, \mathrm{d}}$ & $42.6 \pm 8.3^{\mathrm{b}, \mathrm{d}}$
\end{tabular}

4. Persimmon («Shish Burun», Azerbaijan)

\begin{tabular}{|c|c|c|c|}
\hline 4.1 & Peel & $25.1 \pm 3.2^{\mathrm{b}}$ & $19.3 \pm 4.5$ \\
\hline 4.2 & Pulp & $121.8 \pm 6.6^{\mathrm{a}}$ & BDL \\
\hline \multicolumn{4}{|c|}{ 5. Jerusalem artichoke } \\
\hline 5.1 & Peel & $32.0 \pm 4.2^{\mathrm{a}}$ & $305.7 \pm 10.3^{a}$ \\
\hline 5.2 & Pulp & $0.2 \pm 0.00^{b}$ & $5.3 \pm 1.9^{b}$ \\
\hline \multicolumn{4}{|c|}{ 6. Yellow onion } \\
\hline 6.1 & $\begin{array}{c}\text { Peel } \\
\text { (top layer) }\end{array}$ & $437.0 \pm 10.5^{\mathrm{a}}$ & $2484.2 \pm 49.2^{\mathrm{a}}$ \\
\hline 6.2 & Peel & $107.9 \pm 5.7^{b, c}$ & $779.3 \pm 16.5^{b}$ \\
\hline 6.3 & Pulp & $0.7 \pm 0.0^{6, \mathrm{r}}$ & BDL \\
\hline \multicolumn{4}{|c|}{ 7. White onion } \\
\hline 7.1 & Peel & $3.2 \pm 0.1^{\mathrm{a}}$ & $33.4 \pm 7.8$ \\
\hline 7.2 & Pulp & $0.3 \pm 0.0^{\mathrm{b}}$ & BDL \\
\hline \multicolumn{4}{|c|}{ 8. Crimean onion } \\
\hline 8.1 & Peel & $722.8 \pm 13.9^{a}$ & $3357.5 \pm 42.2$ \\
\hline 8.2 & Pulp & $2.9 \pm 0.2^{\mathrm{b}}$ & BDL \\
\hline
\end{tabular}

* - BDL - below detection limit. a-b, c-d - significant difference between parts of the experimental samples $(\mathrm{P}<0.05)$

It was shown that peels of the plant samples demonstrated the highest antioxidant activity. For example, for quince peel, the antioxidant activity determined by the FRAP method was $232.5 \pm 8.5 \mu \mathrm{mol}$ equiv. Dihydroquercetin / $\mathrm{g}$ of sample, which was higher than the value of pulp and seeds by 27.4 times $(\mathrm{P}<0.05)$ and 75.0 times $(\mathrm{P}<0.05)$, respectively. The absorbance capacity of antioxidants determined by the ORAC method was $918.7 \pm 16.4$ $\mu$ mol equiv. Trolox / $g$ of sample, while in pulp and seeds it was below detection limit.

The antioxidant activity of apple peel determined by the FRAP method was $119.5 \pm 4.8 \mu \mathrm{mol}$ equiv. Dihydroquercetin / $\mathrm{g}$ of sample and exceeded the value pulp and seeds by 5.9 times $(\mathrm{P}<0.05)$ and 1.9 times $(\mathrm{P}<0.05)$, respectively. The absorbance capacity of antioxidants determined by the ORAC method was
$541.3 \pm 29.3 \mu$ mol equiv. Trolox / $\mathrm{g}$ of sample, while in pulp it was below detection limit and in seeds it was $113.7 \pm 15.4 \mu \mathrm{mol}$ equiv. Trolox / $g$ of sample, which was lower than the value of peel by 4.8 times $(\mathrm{P}<0.05)$.

The antioxidant activity of feijoa peel determined by the FRAP method was $302.5 \pm 8.8 \mu$ mol equiv. Dihydroquercetin / $g$ of sample and exceeded the value of pulp and seeds by 2.1 times $(\mathrm{P}<0.05)$ and 6.7 times $(\mathrm{P}<0.05)$, respectively. The absorbance capacity of antioxidants determined by the ORAC method was $553.1 \pm 4.7 \mu \mathrm{mol}$ equiv. Trolox / $g$ of sample and exceeded the value of pulp and seeds by 3.5 times $(\mathrm{P}<0.05)$ and 13.0 times $(\mathrm{P}<0.05)$, respectively.

The antioxidant activity of Jerusalem artichoke peel determined by the FRAP method was 32.0 $\pm 4.2 \mu$ mol equiv. Dihydroquercetin / $\mathrm{g}$ of sample and exceeded the value of pulp by 160 times $(\mathrm{P}<0.05)$. The absorbance capacity of antioxidants determined by the ORAC method was $305.7 \pm 10.3 \mu \mathrm{mol}$ equiv. Trolox / $\mathrm{g}$ of sample and exceeded the value of pulp by 57.7 times $(\mathrm{P}<0.05)$.

The inverse trend was observed regarding persimmon. It was shown that the antioxidant capacity of pulp determined by the FRAP method was $121.8 \pm 6.6 \mu \mathrm{mol}$ equiv. Dihydroquercetin / $\mathrm{g}$ of sample and exceeded the value of peel by 4.9 times $(\mathrm{P}<0.05)$. On the contrary, the absorbance capacity of antioxidants determined in pulp by the ORAC method was below detection limit, while in peel it was $19.3 \pm 4.5 \mu \mathrm{mol}$ equiv. Trolox / $\mathrm{g}$ of sample.

The antioxidant activity of the top layer of yellow onion peel determined by the FRAP method was $437.0 \pm 10.5 \mu$ mol equiv. Dihydroquercetin / $g$ of sample and exceeded the value of lower layer of peel and pulp by 4.1 times $(\mathrm{P}<0.05)$ and 624.3 times $(\mathrm{P}<0.05)$, respectively. The absorbance capacity of antioxidants determined by the ORAC method was $2484.2 \pm 49.2 \mu$ mol equiv. Trolox / $g$ of sample, in pulp it was below detection limit and in the lower layer of peel was equal to $779.3 \pm 16.5 \mu \mathrm{mol}$ equiv. Trolox / $\mathrm{g}$ of sample, which was lower than the value in the top layer of peel by 3.2 times $(\mathrm{P}<0.05)$.

The antioxidant activity of white onion peel determined by the FRAP method was $3.2 \pm 0.1 \mu \mathrm{mol}$ equiv. Dihydroquercetin / $\mathrm{g}$ of sample and exceeded the value of pulp by 10.7 times $(\mathrm{P}<0.05)$. The absorbance capacity of antioxidants determined by the ORAC method was $33.4 \pm 7.8 \mu$ mol equiv. Trolox / $\mathrm{g}$ of sample, in pulp it was below detection limit.

The antioxidant activity of red onion peel determined by the FRAP method was $722.8 \pm 13.9 \mu \mathrm{mol}$ equiv. Dihydroquercetin / $g$ of sample and exceeded the value of pulp by 249.2 times $(\mathrm{P}<0.05)$. The absorbance capacity of antioxidants determined by the ORAC method was $3357.5 \pm 42.2 \mu$ mol equiv. Trolox / $g$ of sample, in pulp it was below detection limit.

The interspecies differences were found concerning onion samples. For example, the maximum antioxidant activity determined by the FRAP method and absorbance capacity of antioxidants determined by the ORAC method were found in red onion peel and were equal to $722.8 \pm 13.9 \mu \mathrm{mol}$ equiv. Dihydroquercetin / $\mathrm{g}$ of sample and $3357.5 \pm 42.2 \mu \mathrm{mol}$ equiv. Trolox / $\mathrm{g}$ of sample, which was higher than the value yellow onion by $65.4 \%(\mathrm{P}<0.05)$ and $35.2 \%(\mathrm{P}<0.05)$, respectively. The detected values in white onion were incommensurably small.

It is known that fruit and vegetable processing generates a huge percentage of plant waste [15]. Peel and husk is one of the main wastes and is a potential perspective source of antioxidants. Obtained results displayed that peels of plant raw materials were characterized by the highest antioxidant capacity. Among the obvious advantages of using such type of waste is low cost of the proposed approach and stimulation of complex processing and rational environmental management. Among plant raw materials, onion, quince and feijoa are the most promising sources of antioxidants, especially their peels.The antioxidant activity of peels of quince, feijoa, bulb and red onion, determined by the FRAP 
method was $232.5 \pm 8.5,302.5 \pm 8.8,437.0 \pm 10.5$ and $722.8 \pm 13.9$ $\mu \mathrm{mol}$ equiv. Dihydroquercetin / $\mathrm{g}$ of sample, respectively; the absorbance capacity of antioxidants determined by the ORAC method was $918.7 \pm 16.4,553.1 \pm 4.7,2484.2 \pm 49.2$ and $3357.5 \pm 42.2$ $\mu \mathrm{mol}$ equiv. Trolox / $\mathrm{g}$ of sample, respectively.

\section{Conclusion}

The interspecies differences were determined concerning onion samples. Red onion peel displayed the maximum antioxidant activity determined by the FRAP method and absorbance capacity of antioxidants determined by the ORAC method equaled to $722.8 \pm 13.9$ umol equiv. Dihydroquercetin / $\mathrm{g}$ of sample and $3357.5 \pm 42.2 \mu \mathrm{mol}$ equiv. Trolox / $\mathrm{g}$ of sample, respectively, which was higher than the value of yellow onion by $65.4 \%(\mathrm{P}<0.05)$ and $35.2 \%(P<0.05)$, respectively. The detected values in white onion were incommensurably small.

The obtained data confirmed the efficiency of use waste of fruit and vegetable industry as a source of natural antioxidants, which are safe and are in demand as food-grade preservatives. In addition, this raw material is easily available and cost-effective, and facilitates an improvement of ecological situation due to reduction of waste volumes by their processing.

\section{REFERENCES}

1. Food Loss and Food Waste. [Electronic resource: http://www.fao.org/ food-loss-and-food-waste/ru/ Access date 19.08.2019] (in Russian)

2. Lukinova, E.A., Kotenkova, E.A., Makarenko, A.N. (2017). Antimicrobial substances: an alternative approach to the extension of shelf life. Theory and practice of meat processing, 2(3), 4-20. DOI: 10.21323/2414438X-2017-2-3-4-20 (in Russian)

3. Esimbekova, E.N., Asanova, A.A., Deeva, A.A., Kratasyuk, V.A. (2017). Inhibition effect of food preservatives on endoproteinases. Food Chemistry, 235, 294-297. DOI: 10.1016/j.foodchem.2017.05.059

4. Kalpana, V.N., Rajeswari, V.D. (2019). Preservatives in Beverages: Perception and Needs. Chapter 1 in the book Preservatives and Preservation Approaches in Beverages, 15, 1-30. ISBN 9780128166857

5. Mohammadzadeh-Aghdash, H., Akbari, N., Esazadeh, K., Ezzati Nazhad Dolatabadi, J. (2019). Molecular and technical aspects on the interaction of serum albumin with multifunctional food preservatives. Food Chemistry, 393, 491-498. DOI: 10.1016/i.foodchem.2019.04.119

6. Onishchuk, D.I., Zhukov, V.V. (2012). The use of food addition as additives in population nutrition. Bulletin of medical Internet-conferences, 2(2), 67. (in Russian)

7. Titova, N.D. (2008). Food addition as alimentary allergens. Immunopathology, Allergology, Infectology., 2, 41-46. (in Russian)

8. Blagoveshchenskaya, D.B., Merzlyakov, A.S. (2011). Studying toxic properties of widespread modern preservatives. Journal of New Medical Technologies, 18(2), 501-502. (in Russian)
9. Konovalov, K.L., Shulbaeva, M.T. (2008). Vegetative food composites for manufacturing of combined products. Food Industry, 7, 8-12. (in Russian)

10. Pogosyan, D.G., Gavryushyna, I.V., Shyshkina, T.V. (2014). Application of dehydroquercitin for curds production. Dairy Industry, 7, 62-63. (in Russian)

11. Reshetnik, E.I. (2011). Substantiation and development of the food production technology with the use of dihydroquercetin. Agricultural Journal in the Far East Federal District,1(1),130-132. (in Russian)

12. SP\&A Application Laboratory (2016) Determination of Antioxidant Capacity on the Thermo Scientific Varioskan LUX Multimode Reader Thermo Fisher Scientific [Electronic resource: https://assets.thermofisher. com/TFS-Assets/LED/Application-Notes/Antioxidant-Capacity-AN-VarioskanLUX-ORAC-EN.pdf/ Access date 05.08.2019]

13. Kupaeva, N.V. (2018). Determination of general antioxidant capacity of vegetable food additives. Proceedings of the 12th International scientificpractical conference of young scientists and specialists of organizations in the sphere of agricultural sciences, 183-189. (in Russian)

14. Gimadieva, A.R., Khazimullina, Yu.Z., Belaya, E.A., Zimin, Yu.S., Abdrakhmanov I.B., Mustafin, A.G. (2015). Express evaluation of antioxidant activity of uracil derivatives. Biomedical Chemistry, 61(6), 765-769. DOI: 10.18097/PBMC20156106765 (in Russian)

15. Cleaning of fruit and vegetable raw material before drying. [Electronic resource: http://www.activestudy.info/ochistka-plodoovoshhnogo-syryapered-sushkoj Access date 19.08.2019] (in Russian)

\section{AUTHOR INFORMATION}

Nadezhda V. Kupaeva - bachelor of chemistry, student of Dmitry Mendeleev University of Chemical Technology of Russia, laboratory assistant of Experimental clinic - research laboratory of biologically active substances of an animal origin. V.M. Gorbatov Federal Research Center for Food Systems of Russian Academy of Sciences, 109316, Moscow, Talalikhina str., 26. Tel.: +7-966-359-19-00 E-mail: NVkupaeva@yandex.ru *corresponding author

Elena A. Kotenkova - candidate of technical sciences, research scientist of Experimental clinic - research laboratory of biologically active substances of an animal origin. V.M. Gorbatov Federal Research Center for Food Systems of Russian Academy of Sciences,

109316, Moscow, Talalikhina str., 26. Tel.: +7-495-676-92-11, E-mail: lazovlena92@yandex.ru

Authors are equally relevant to the writing of the manuscript, and equally responsible for plagiarism

The authors declare no conflict of interest

Received 20.07.2019 Accepted in revised 30.08.2019 Accepted for publication 10.09.2019 